\title{
Güç Sistemindeki Harmoniklerin Bilgisayar Destekli Modellenmesi
}

\section{Computer Aided Modelling of Harmonics in the Power System}

\section{Sabir RÜSTEMLI' ${ }^{*}$, Sinan TEKEV ${ }^{2}$}

${ }^{1}$ Bitlis Eren University, Bitlis, Turkey, srustemli@ beu.edu.tr, ORCID: 0000-0002-4957-1782

${ }^{2}$ Bitlis Eren University, Bitlis, Turkey, sinantekev@hotmail.com, ORCID: 0000-0002-4486-4383

\begin{tabular}{|c|c|}
\hline MAKALE BİLGİLERİ & ÖZ \\
\hline Makale Geçmişi: & \multirow{11}{*}{ 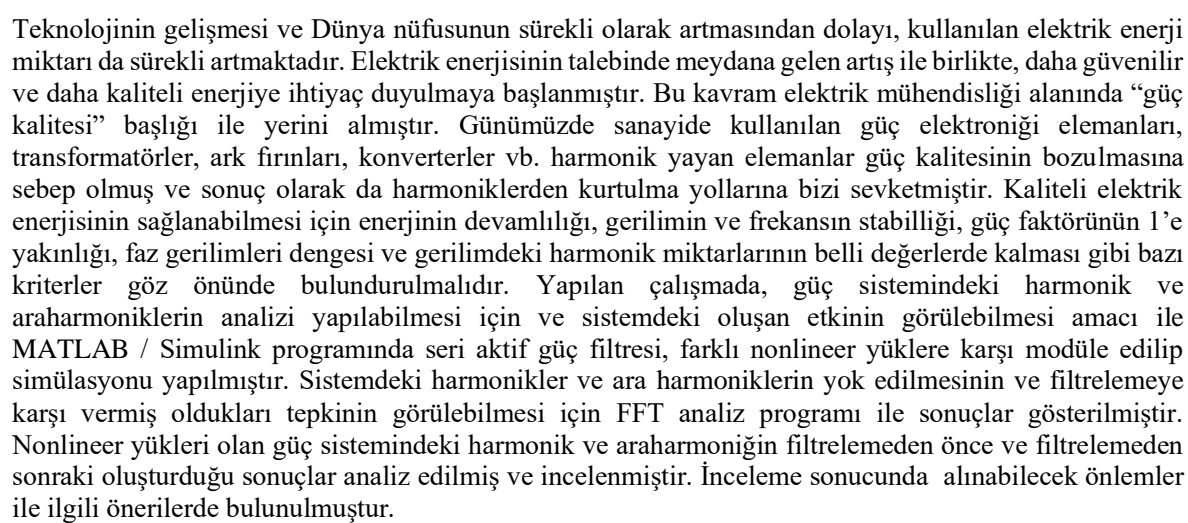 } \\
\hline Geliș 22 Eylül 2021 & \\
\hline Revizyon 27 Aralık 2021 & \\
\hline Kabul 28 Aralık 2021 & \\
\hline Online 31 Aralık 2021 & \\
\hline Anahtar Kelimeler: & \\
\hline Güç Sistemleri, Harmonikler, & \\
\hline & \\
\hline & \\
\hline & \\
\hline & \\
\hline
\end{tabular}

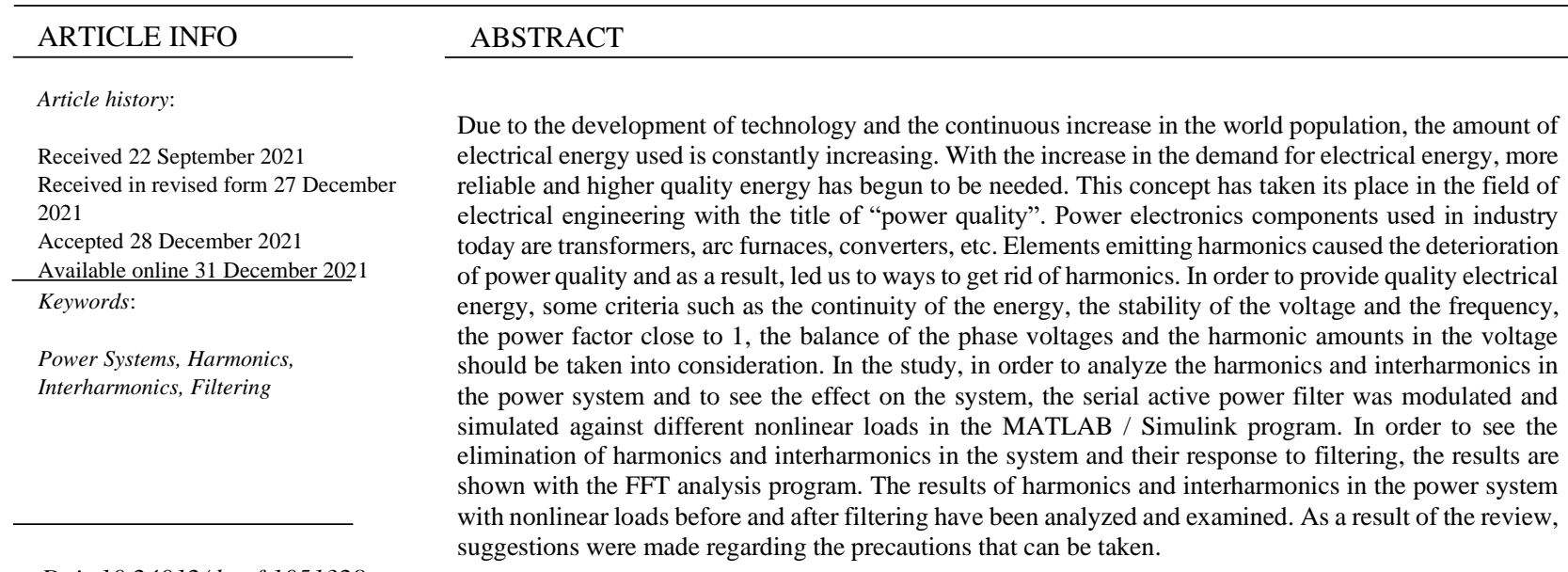




\section{GíRiş}

Elektrik enerjisinin üretim, iletim ve dağıtım aşamalarında akım ve gerilim büyüklüklerinin sinüs dalgası biçiminde olması gerekiyor. Fakat bu her zaman gerçekleşmeyebilir. Enerji sistemlerinde manyetik ve elektrik devre nonlineerliğ harmoniklere neden olmaktadır. Harmonikler, üretilen enerjinin kalitesinde önemli bir etkendir. Akım ve gerilim dalga biçiminin sinüs dalga biçiminden uzaklaşması şeklinde tanımlanabilecek olan harmonikler, nonlineer elemana sinüzoidal bir kaynağın uygulanması yoluyla ya da nonsinüzoidal bir kaynaktan beslenen lineer veya nonlineer elemanlar tarafindan oluşturulur [1].

Rüstemli vd. [2] Harmonikleri azaltmanın veya yok etmenin en önemli ve faydalı yöntemi harmonik filtreler kullanmaktır. Çalışmalarında Türkiye'nin doğusunda yer alan Van şehrinde bulunan iki farklı fabrikada, Zera MT310'un güç analizörü yardımıyla ölçümleri gerçekleştirilen (harmonikler, anlık elektriksel değerler, akım ve gerilim dalga şekilleri) gibi çeşitli parametrelerin farklı tarihlerde olmak üzere detaylı bir incelemesi yapılmıştır. Rüstemli vd. [3] Pasif filtre sisteminin yapısı ve uygulama şekilleri hakkında bilgiler verilmiştir. Enerjide harmoniklerin filtrelemesinde kullanılan (endüktans bağlı kompanzasyon sistemi) sistemleri verilmiştir. Dağıtım sisteminin çeşitli noktalarında harmonik analizörü Simplorer Simulation Center 6.0 (SSC 6.0) programı ile ölçüm yapılmıştır. Enerji sisteminin güç elektroniği uygulamalarında başarılı sonuçları elde edilmiştir. Rüstemli vd. [4] ZERA MT 310 sinyal analizörü kullanılarak güç kayıplarındaki parametreleri (gerilim dalga şekilleri, harmonikler) tespit edilmiştir. Güçteki bu istenmeyen kayıpların sebeplerini araştırılmıştır. Simplorer 6.0 program ile seri aktif filtrenin modellemesi yapılarak incelenmiştir.

Şahin [5] Harmonik kaynaklar, harmoniklerin güç sistemlerindeki etkileri ve harmoniklerin süzülmesine ilişkin bilgi vermiştir. Harmonik analizi için geliştirilmiş olan algoritma ve akış diyagramı ile kullanılan yazılım açıklanmıştır. Şahin [6] çalışmasında harmoniklerin yeraltı güç kabloları üzerine etkilerinin tespit edilmesi ve harmonik etkilerinin düşürülmesi adına önerilerde bulunmuştur. $\mathrm{Bu}$ noktada bir OG sistemde harmonik ölçümü yapılarak, elde edilen değerler doğrultusunda bir MATLAB/SIMULINK modeli oluşturulmuştur.

Yapılan çalışmada farklı tipte yüklere sahip bir güç sistemi için harmoniklerin ve araharmoniklerin kıyaslanıp incelenmesi yapılmış olup alınabilecek önlemler planlanmıştır. Güç sisteminde meydana gelen sonucu görmek için ve harmonik ve araharmoniğin gösterilebilmesi için MATLAB/Simulink programıla modüle edilip, simülasyonu yapılarak belirtilmiştir. Bu çalışmada amaç, güç sistemi üzerindeki harmonik ve araharmoniğin sonuçlarının analiz edilip neler yapılabilirliğinin incelenerek ilgili önerilerde bulunulmasıdır.

\section{HARMONIKLERIN FILTRELENMESI}

Harmoniklerin oluşmasına neden olan kaynaklar; Döner makineler, Transformatörler, Güç elektroniği elemanları, Doğru akım ile enerji nakli, Statik VAR generatörleri, Ark firınları, Kesintisiz güç kaynakları, Fotovoltaik sistemler, Konverterler, Elektronik balastlar ve Gaz deşarjlı aydınlatma şeklinde sıralanabilir.
Harmonikler; genellikle nonlineer elemanlar ve nonsinüzoidal kaynaklardan birinin ya da her ikisinin de sistemde mevcut olmasından kaynaklanmaktadır. Harmonikli akım ve gerilimin güç sistemlerinde mevcut olması sinüzoidal dalganın bozulmasına yol açacaktır. Bu bozulan dalgalara, nonsinüzoidal dalga adı verilmektedir. Harmonikler güç sistemlerinde; rezonans olayları, ek kayıplar, ek gerilim düşümleri, güç faktörünün değişmesi gibi teknik ve ekonomik sorunlara sebep olur. Sinüzoidal alternatif akım uygulanan bir alıcının şebekeden harmonikli akım çekmesi, bu alıcının yapısının gerektirdiği bir durumdur. $\mathrm{Bu}$; alıcının nominal çalışması esnasında harmonik meydana getirerek akım çekmesi demektir. Harmonik üreten bu alıcıların dışında, lineer karakteristikte olmalarına karşın harmonikli akımlara yol açan alıcılar da mevcuttur. Bu da, alıcıya uygulanan gerilimin nonsinüzoidal oluşundan kaynaklanmakta olan bir durumdur. Alternatif akım üretimi esnasında alternatörlerde alınan iyileştirici önlemlerle, elektrik enerjisinin sinüzoidale mümkün olduğunca yaklaştırılması sağlanmaktadır. Ancak, aynı şebekeye bağlı diğer nonlineer yükler, lineer bir alıcıya etki edebilmektedir [7].

Enerji sistemlerinde, harmonikler nedeniyle gerilim ve akım dalga şekillerinde yaşanan bozulmalar birçok farklı soruna sebebiyet vermektedir. Bu sorunlar; Enerji sistemindeki elemanlarda ve yüklerdeki kaybın artışı, Generatör ve şebeke geriliminin bozulması, Gerilim düşümünde artış, Kompanzasyon tesislerinin aşırı reaktif yüklenme ve dielektrik zorlanma sebebiyle hasar görmesi, Uzaktan kumanda, yük kontrolü gibi yerlerde ortaya çıkan çalışma bozuklukları, Şebekede rezonans olayları, rezonansın yol açtığı aşırı gerilimler ve akımlar, Senkron ve asenkron motorlarda moment salınımlarının ve aşırı ısınmanın ortaya çıkması, Endüksiyon tipi sayaçlarda yanlış ölçümler, İzolasyon malzemesinin delinmesi, Ateşleme devrelerinin anormal çalışması, Elektrik aygıtlarının ömrünün azalması, Makinelerde mekanik titreşimler (vibrasyon), Sesli ve görüntülü iletişim araçlarında parazit ve anormal çalışma, Mikro bilgi işlemciler üzerinde hatalı çalışma, Elektronik kart arızaları, Elektromekanik cihazlarda ve kablolarda 1sınma, $\mathrm{CAD} / \mathrm{CAM}$ terminallerinde hafiza silinmesi, Kesici ve şalterlerde açmalar, Kompanzasyon sigortalarının atması, Güç kondansatörlerinde güç kayıpları, delinmeler ve patlamalar, Röle sinyallerinin bozulması ve anormal çalışması ve Enerji kayıpları şeklinde sıralanabilir [8]. Kullanıcıların sistemi kirletmelerine ve birbirlerine zarar verecek etki yaratmalarına izin verilmesi düşünülemez, bu nedenle ülkelerin çoğunda elektrik dağıtımı yapan kuruluşlar çekilecek harmonik akım miktarını sınırlayan kurallar koymuşlardır [9].

Endüstrileşmenin bir sonucu olarak elektrik şebekelerinde meydana gelen kirlenme kaçınılmaz bir durumdur. Enerji kalitesi üzerinde belirleyici rol oynayan başlıca faktörler; gerilim değişimleri, kesintiler ve temel frekans dışındaki frekansları (harmonikleri) üreten tüketicilerdir. Harmoniklerden kaynaklı olası zararlı etkilerin önüne geçilmesi yalnızca tasarım aşamasında alınacak önlemlerle mümkün olabilmektedir. Harmonik akımların şebekeye geçmesini engellemek adına ek devrelere gereksinim duyulmaktadır. Devreye yerleştirilen ve istenen harmonik akımının süzülmesini sağlayan bu devreler, 'harmonik 
filtresi’ olarak adlandırılır. Harmonik filtreler, bir veya daha fazla frekanstaki akımın veya gerilimlerin yani harmoniklerin etkisini azaltmayı amaçlar. Bu filtrelerin görevi, kısaca; harmonik üreten bir cihazın beslediği yükün gerilim dalgalarını düzelterek, AC sisteme katılan istenmedik harmonik bileşenlerin önüne geçmektir [10, 11, 12].

Endüstriyel tesislerde gerilimde meydana gelen bozulmanın $\% 5$ 'in üzerinde olmaması genellikle kabul edilir olup pasif filtreler aracılığıyla bu seviyeye inilebilir. Fakat hava alanı ve hastanelerde gerilimde meydana gelen bozulma $\left(\mathrm{THD}_{\mathrm{v}}\right) \% 3$ oranının altında olmalıdır. $\mathrm{Bu}$, her zaman pasif filtre ile sağlanamayabilir. Böyle bir durumda aktif filtrelere ihtiyaç duyulur.

\subsection{PASIF FÍLTRELER}

Pasif filtreler kaynak ve yük arasına yerleştirilen ve temel frekans dışındaki bileşenlerin yok edilmesine yönelik olarak tasarlanan ve kondansatör, endüktans ve kimi durumlarda direnç elemanlarından oluşan devrelerdir. Pasif filtreler, ortadan kaldırılmak istenen harmonik bileşen frekansında rezonansa gelecek $\mathrm{L}$ ve $\mathrm{C}$ değerlerinin belirlenmesini amaçlar. Her bir harmonik için ayrı devre tasarımı yapılır. Pasif filtreler; seri pasif filtreler ve parelel (şönt) pasif filtreler olmak üzere 2 ayrı bölümde incelenir. Değişik pasif filtre çeşitleri Şekil 1'de gösterilmiştir. Seri pasif filtreler harmonik kaynağı ile şebeke arasına seri olarak bağlanır. İstenmeyen harmonik bileşen işaretlerini geçirmemek için yüksek bir seri empedansın kullanımıyla sistemde istenmeyen harmonik işaretlerini engeller. Yalnızca belirli frekansa sahip harmonik işaretleri engeller. Seri filtreler, filtrelerde rezonans durumu gözlenmemesine karşın, tam yük akımını taşıma ve hat gerilimine göre yalıtım zorunlulukları mevcuttur. Şekil 2'de seri filtrenin devreye bağlanış şekli gösterilmiştir [13].
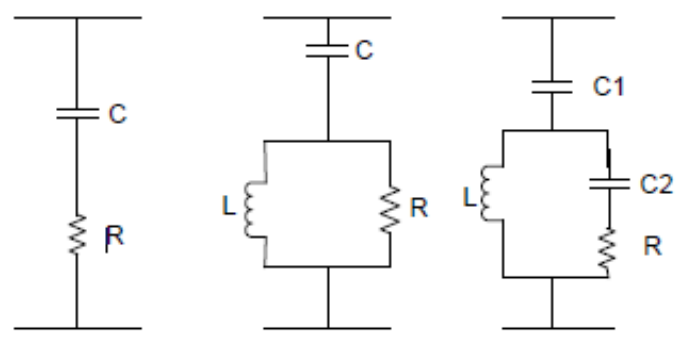

Şekil 1. Değişik pasif filtre çeşitleri

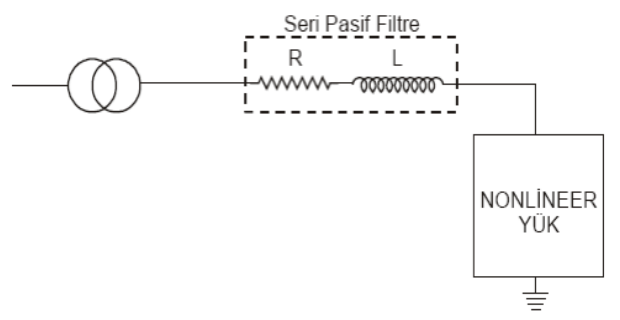

Şekil 2. Bir devrede seri filtrenin kullanımı

Seri filtreler pratikte AC motor sürücü devrelerinin ve yüksek güçlü AC/DC inverterlerin önlerinde kullanılır. Seri filtrenin uygulanmasındaki zorluk; tüm yük akımının filtre üzerinden geçmesi olup, tam hat gerilimleri için yalıtılmasının gerekmesi ve gerilim düşümüne sebebiyet vermesidir [8].
Parelel filtreler harmonik kaynağına parelel bağlanır. Parelel pasif filtreler, ortadan kaldırılmak istenen harmonik bileşen frekansı için rezonansa gelecek $\mathrm{C}$ ve $\mathrm{L}$ değerlerini hesaplayarak bu devreyi kaynağa bağlamayı amaçlar. Her bir harmonik frekansı için bu hesaplama ayrı ayrı yapılır ve oluşturulan devre kaynağa bağlanır. Bu işlem genlik değeri yüksek harmonik frekansları için yapılmalıdır. Bunun nedeni her harmonik için yapılması optimum bir çözüm sağlamamasıdır. Genliği düşük olan harmonik işaret frekansları için bunların etkinliğini azaltacak tek bir rezonans kolu oluşturmak yeterlidir. Şekil 3'de paralel filtrenin devreye bağlanış şekli gösterilmiştir [14].

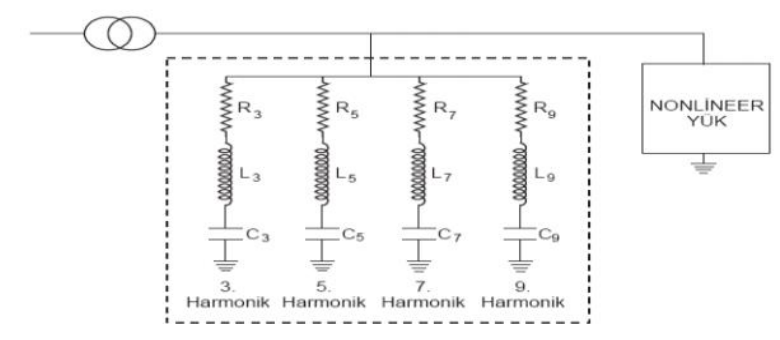

Şekil 3. Bir devrede paralel filtrenin kullanımı

\subsection{AKTİF FILTRELER}

Aktif güç filtresi genel kullanım sebebi olarak, tüketicilerinin her biri için kendisinin de bir harmonik kaynak olan yüklerinin akım gerilim dengesizliğini elimine etmektir. Diğer taraftan fabrikalar için kullanılan aktif güç filtresi temelde, güç dağıtım sistemlerindeki harmonik değerleri azaltmayı ve bu şekilde gerilim harmonikleri ve gerilim dengesizliklerini ortadan kaldırmayı amaçlar [15]. Aktif filtrenin çalışma yöntemi pasif filtrenin çalışma yönteminden bütünüyle farklıdır. Aktif filtre şebekedeki harmonikleri hesaplayarak, onlara aynı genlikte ters fazda harmonik üretir. $\mathrm{Bu}$ şekilde güç kalitesine etki eden harmonikleri yok eder. Aktif filtre var olan harmoniklerin ortadan kaldırılmasını sağlayacak harmoniklerin üretiminden sorumlu olup, aşırı yüklenme olasılığı taşımamaktadır. Kapasitenin üstündeki harmonikler şebekede dolaşmayı sürdürerek, aktif filtre kapasitesi mertebesinde harmoniklerin üretilmesine yani çalışmaya devam eder.

Aktif filtreler yapıları bakımından; paralel, seri ve hibrit güç filtreleri olmak üzere 3 bölümde incelenir. Kontrol yöntemine göre de açık çevrim ve kapalı çevrim aktif güç kontrol sistemi olarak iki farklı bölüm altında ele alınmaktadır.

Paralel aktif güç filtresi (PAGF), şebekeye paralel bağlanır. Filtre çeşitlerinden bu tür, sanayi işletmelerindeki en önemli ve en geniş kullanım alanına sahip yapılardır [16]. Bu filtreler harmonik akım filtrelemesi, reaktif güç kompanzasyonu, yük akımı dengelemesi ve nötr akım kompanzasyonu gibi akım kaynaklı harmoniklerin eliminasyonu için elverişlidir [17]. Şekil 4'de temel bir PAGF gösterilmektedir.

Paralel aktif güç filtrelerinin dezavatajları yüksek güçlü uygulamalarda oluşmaktadır. Çünkü yüksek güç uygulamalarında, aktif filtrelerde kullanılacak yarı iletken sikıntısı meydana gelmektedir. $\mathrm{Bu}$ uygulamalarda transformatörler, çoklu konvertörler veya kaskat bağlama 
konvertörleri PAGF ve elektrik güç şebekesi değerlerinin birleşmesi için kullanılması gerekmektedir [16].

Seri aktif güç filtresi (SAGF) şebeke ile bağlantılı bir trafo üzerinden seri bağlanır. Seri aktif güç filtresi temel olarak anlık gerilim giriş çıkıșıyla yük boyunca saf sinüzoidal gerilim dalga formunun stabilizasyonun sağlanmasına dayalıdır [16]. Bu filtreler gerilim harmonik kompanzasyonu, gerilim regülasyonu, gerilim dengelenmesi, gerilim dalgacıklarının azalması ve gerilim düşmelerinin yok edilmesi için kullanılır [18]. Bu, yük üzerinde saf sinüzoidal dalga formu sağlar ki bu da gerilim değişimlerinde hassas olan cihazlar için oldukça önemlidir. PAGF ${ }^{e c}$ in SAGF'a karşı en büyük dezavantajı üzerindeki çıkış gerilim dalgasının sinüzoidal biçimini devam ettiremiyor olmasıdır. Bu durum SAGF'1 ideal hale getirmektedir [16]. Bununla beraber, SAGF transformatör bağlantılarının tamamını yük akımları üzerinden geçireceğinden, yüksek kapasiteye sahip olması gerekmektedir. Harmonik akımların yüksek olduğu durumlarda, aktif güç filtresinin kapasitesi de artmaktadır. Şekil 5'de temel bir SAGF gösterilmektedir.

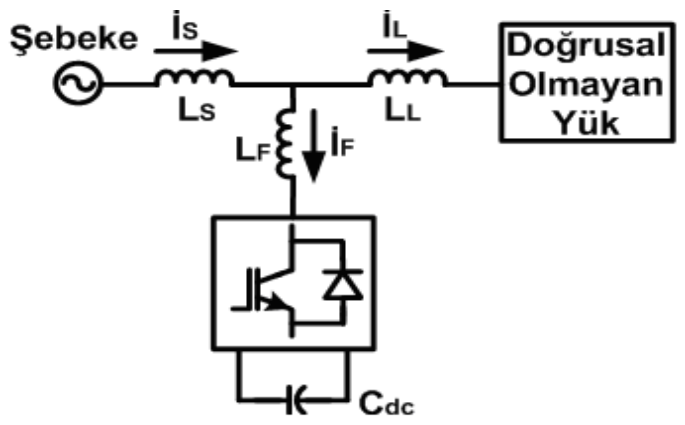

Şekil 4. Paralel aktif güç filtresi

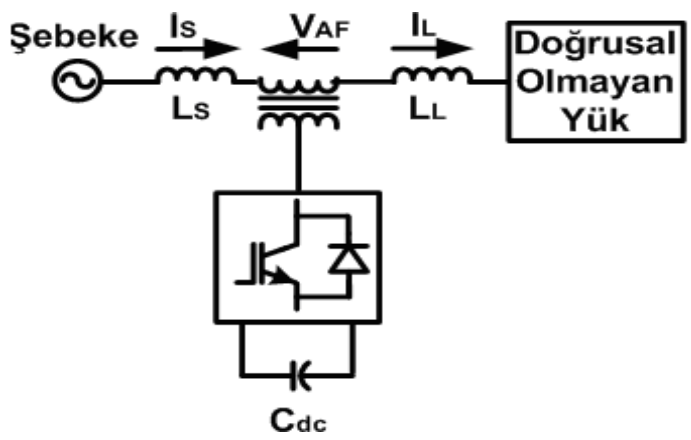

Şekil 5. Seri aktif güç filtresi

Hibrit aktif güç filtresi (HAGF), aktif güç filtresi ve pasif güç filtresinin bağlantı yapılarının birleşimiyle meydana gelen filtre yapısıdır. HAGF sadece harmonik kompanzasyonu için kullanılmasının yanında, gerilim regülasyonu, güç kompanzasyonu, kaynak ve harmonik kaynaklı yük arası izolasyon için de kullanılmaktadır. Bu filtrelerin esas amacı, maliyeti azaltmak ve etkinliğini artırmaktır. PAGF'ın PPF ile bileşimi, PAGF ile beraber paralel pasif filtre veya yüksek geçişli filtrenin oluşumudur. Bunun için kullanılan PAGF düşük salınımlı harmoniklerin eliminasyonuna yönelik modellenirken, PPF yüksek salınımlı harmoniklerin kompanzasyonuna yönelik olarak modellenir [16]. Yüksek sıralı harmoniklerin kompanzasyonu adına, anahtarlama frekansı sınırlandırılır. Eş zamanlı olarak, bunun için kullanılan PAGF, PPF ile kaynak empedansı arasındaki olası rezonansın elimine edilmesi için kullanılmaktadır [19]. Şekil 6'da, PPF ve PAGF ile oluşan temel bir hibrit aktif güç filtresini göstermektedir.

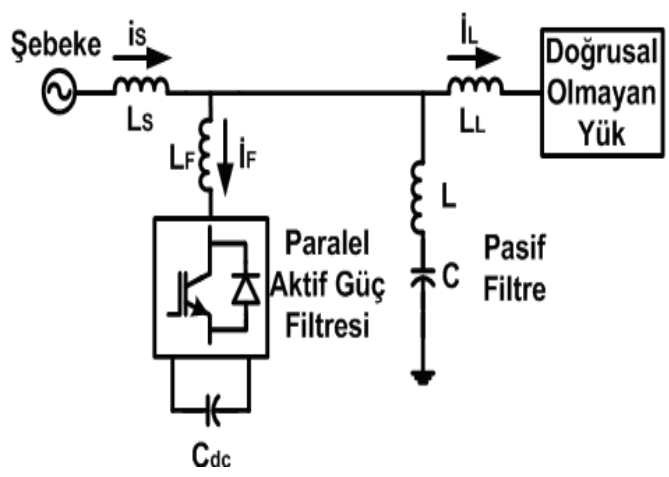

Şekil 6. Hibrit aktif güç filtresi

Hibrit aktif güç filtresinin tekniğindeki başlıca dezavantajı, PPF için çok sayıda güç bileşenine sahip olmasıdır. Burada, PPF sürekli sisteme bağlandıklarından lineer olmayan kaynakları önceden bilinen yükler için uygundur [16].

\section{MATLAB/Simulink}

Simulink, çok alanlı simülasyon ve model tabanlı tasarım için bir blok diyagram ortamıdır. Sistem düzeyinde tasarımı, simülasyonu, otomatik kod oluşturmayı ve gömülü sistemlerin sürekli test edilmesini ve doğrulanmasını destekler. Simulink, bir grafik editörü, özelleştirilebilir blok kütüphaneleri ve dinamik sistemlerin modellenmesi ve simülasyonu için çözücüler sağlar. Özetle, simulink ile kod yazmadan blok diyagramlar kullanılarak simülasyon yapılabilmektedir. Simulink'in kullanıldığı alanlardan birkaçı; Görüntü işleme uygulamaları, Kontrol sistemleri (PID kontrolü), Sayısal işaret işleme, Elektrik devre çözümü, Durum-uzay modelleri ve Transfer fonksiyonları şeklinde siralanabilir.

Simulink ortamında kullanılan seri aktif güç filtresi, tetikleme blok şeması Şekil 7'de görülmektedir. Şekil 8'de ise seri aktif güç filtrenin fourıer dönüşümü simulink modellemesi ile oluşturulan iç yapısı blok şeması verilmiştir [20].

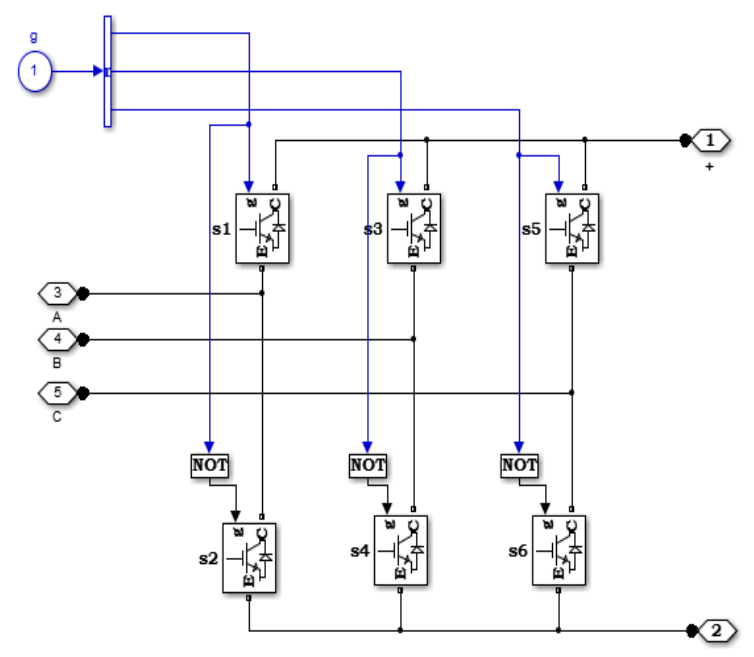

Şekil 7. Seri aktif filtre tetikleme blok şeması 


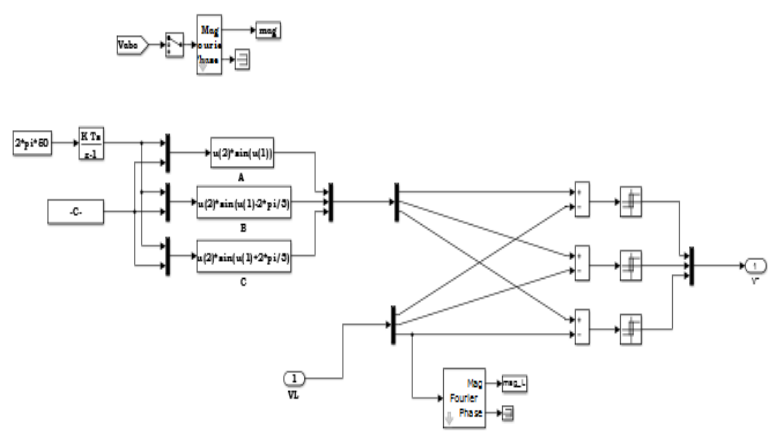

Şekil 8. Seri aktif güç filtre iç yapısı blok şeması

Şekil 9'da Non-Lineer kapasitif yükün Matlab/ Simulink blok şeması verilmiştir [20].

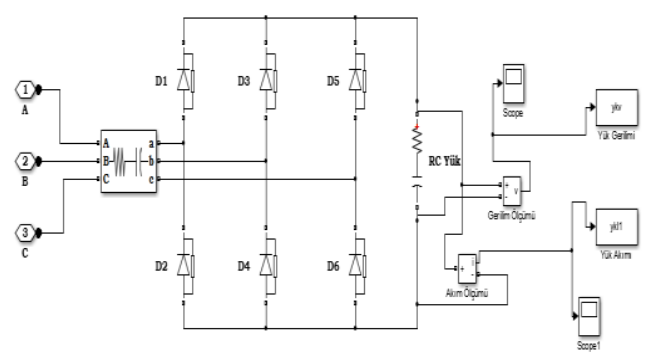

Şekil 9. Nonlineer kapasitif yükün Matlab/Simulink şeması

Matlab/Simulink programında örnek alınan sistemin seri aktif güç filtre ile modellemesi ve simülasyonu yapılarak harmonik ve araharmonik bozulması incelenmiş ve eliminasyonu yapılmıştır. Tabloler halinde veriler sunulmuş, karşılaştırılarak sonuçlar gösterilmiştir.

İncelenen modül yapı gerilimin üç fazlı bir dağıtım şebekesinden alındığ 1 , fazların herbirinin $380 \mathrm{~V}$ AC olarak alındığı, yükün fazlara eşit olarak dağıldığı bir sistemdir. Seçilen sistem parametreleri Tablo 1'de gösterilmiştir.

Tablo 1. Sistem modüle edilirken SAGF parametreleri

\begin{tabular}{|l|c|}
\hline \multicolumn{1}{|c|}{ SAGF Parametreleri } & Değer \\
\hline $\begin{array}{l}\text { Kaynak Gerilimi ve Akımı (Va, } \\
\text { Vb, Vc, Ik) }\end{array}$ & $380 \mathrm{~V}, 60 \mathrm{~A}$ \\
\hline Kaynak Frekansı & $50 \mathrm{~Hz}$ \\
\hline Kaynak Empedansı (Rk, Ck) & $1 \Omega, 100 \mathrm{e}-6 \mathrm{~F}$ \\
\hline Yük Empedansı (Ry, Ly) & $55 \Omega, 0.20 \mathrm{e}-3 \mathrm{H}$ \\
\hline Yük Empedansı (Ry, Cy) & $55 \Omega, 5 \mathrm{e}-6 \mathrm{~F}$ \\
\hline
\end{tabular}

Çalışmanın amacı harmonik ve araharmoniklerin modüle edilerek belirlenmesi ve harmoniklerin yok edilmesi olduğundan filtrenin Şekil 10'da verilen Güç Sistemi
MATLAB/Simülink programında sistem yükü tasarlanarak analiz için sonuçlar elde edilmiştir.

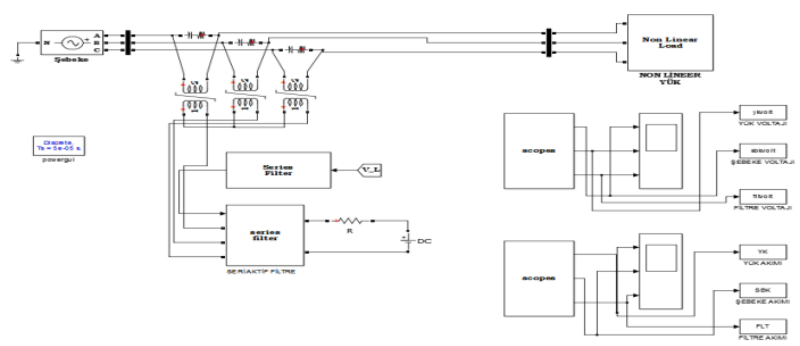

Şekil 10. Güç sistemi Matlab/Simulink şeması

Şekil 11'de Nonlineer kapasitif yüklü, filtresiz güç sistemine ait Matlab/Simulink şeması, Şekil 12'de Kapasitif yüklü filtresiz sisteme ait gerilim dalga verileri verilmiştir.

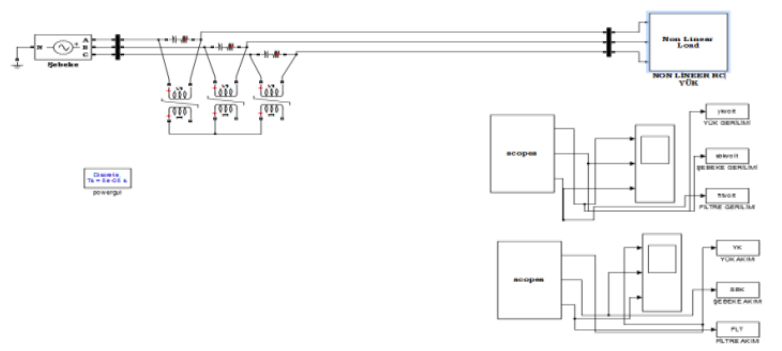

Şekil 11. Nonlineer kapasitif yüklü , filtresiz güç sistemine ait Matlab/Simulink şeması

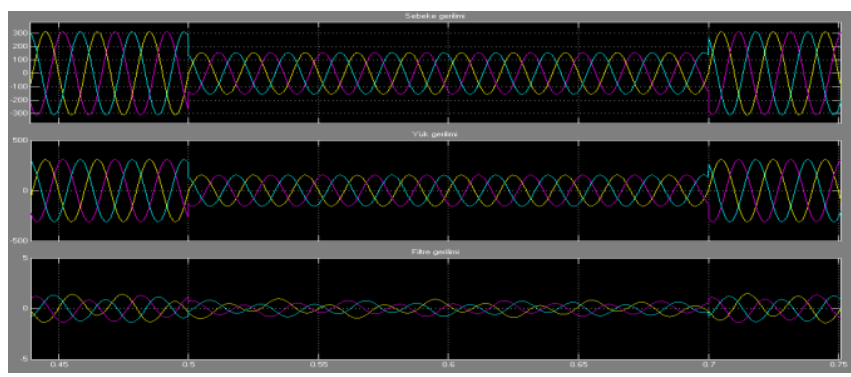

Şekil 12. Kapasitif yüklü filtresiz sisteme ait gerilim dalga verileri

Şekil 12'ye bakacak olursak yük geriliminin filtresiz sisteme ait olduğu gerilim dalga verilerinin örnek zaman olarak (0.40.8) t sürelerinde harmoniğe maruz kalarak genliğinin düştüğünü 250 V'tan 150 V'a düştüğü ve sinüzoidal dalga şeklini koruyamayıp, filtremizin devrede olmadı̆̆ gerekli ters fazda sisteme akım gönderip regüle yapamadığı görülmektedir. Şekil 13'de Kapasitif yüklü filtresiz sistemin FFT sistemi analiz diyagramı verilmiştir.

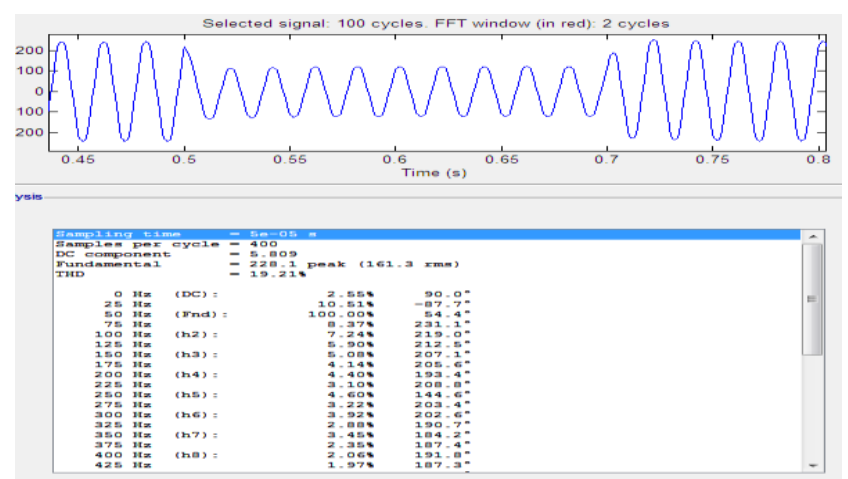

Şekil 13. Kapasitif yüklü filtresiz sistemin FFT sistemi analiz diyagramı 
Şekil 13'e bakacak olursak filtrelenmemiş sistemin yine FFT sistemi analiz diyagramına bakılırsa görülen $\mathrm{THD}_{\mathrm{v}}$ oranının \%19.21 olduğu ve $n$. harmoniğin dışındaki araharmoniklerinde varlığının olduğu görülmektedir. Sistemdeki bozulmayı gösterebilmek, harmonik ve araharmonikteki karşılaştırmayı ve harmoniklerin yok edilmesini daha iyi gösterebilmek için seri aktif güç filtresi devredeyken incelenmiş ve sonuçlar yansıtılmıştır. Şekil 14'de kapasitif yüklü filtresiz güç sisteminin FFT sistemi ile genlik spektrumu görünümünü gösterilmektedir.

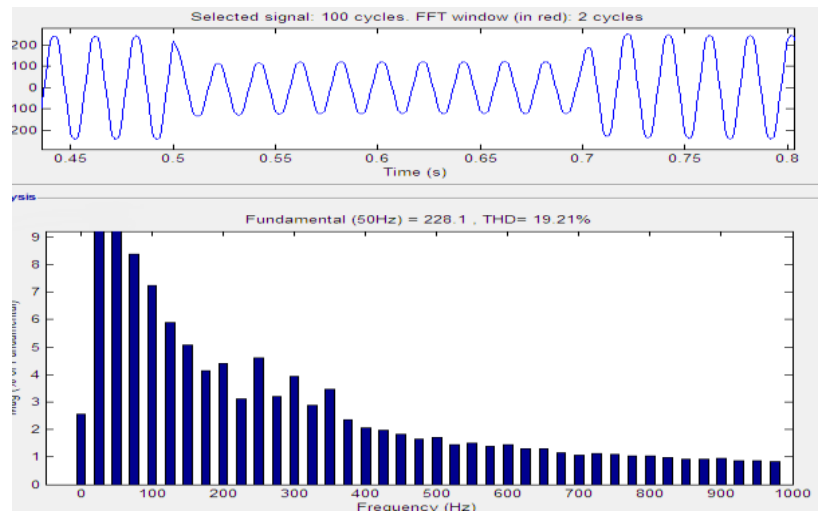

Şekil 14. Kapasitif yüklü filtresiz sistemin FFT sistemi genlik spektrumu

Şekil 15'de SAGF filtreli kapasitif yüklü güç sistemine ait Matlab/Simulink şeması verilmiştir. Şekil 16'da ise Kapasitif yüklü filtreli sistem gerilim dalga verileri gösterilmiştir.

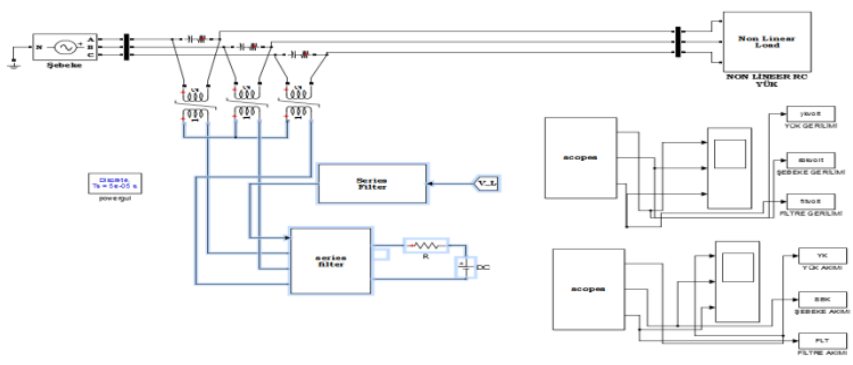

Şekil 15. SAGF filtreli kapasitif yüklü güç sistemine ait Matlab/Simulink şeması

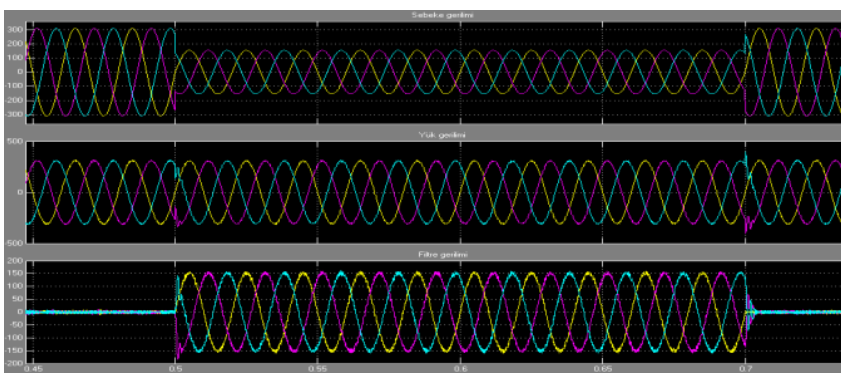

Şekil 16. Kapasitif yüklü filtreli sistem gerilim dalga verileri

Şekil 16'ya bakacak olursak seri aktif güç filtresi kapasitif yükteki sistemde varken gerilim dalga verisinin stabilizasyonu için örnek zaman olarak (0.4-0.8) t aralıklarında yük için 250 V'daki gerilimi korumak için genlik değerlerinin dengeye girebilmesi için $100 \mathrm{~V}$ luk genlik arttırıp harmoniklere karşı koyduğu görülmektedir.

Kapasitif yüklü filtreli sistemin FFT sistemi analiz diyagramı Şekil 17'de verilmiştir.

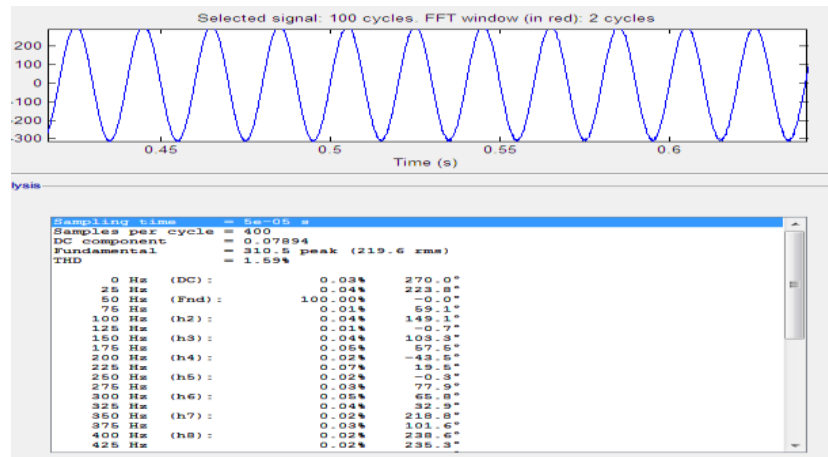

Şekil 17. Kapasitif yüklü filtreli sistemin FFT sistem analiz diyagram 1

Kapasitif yüklü filtreli sistemin FFT sistemi genlik spektrumu şekil 18'de verilmiştir.

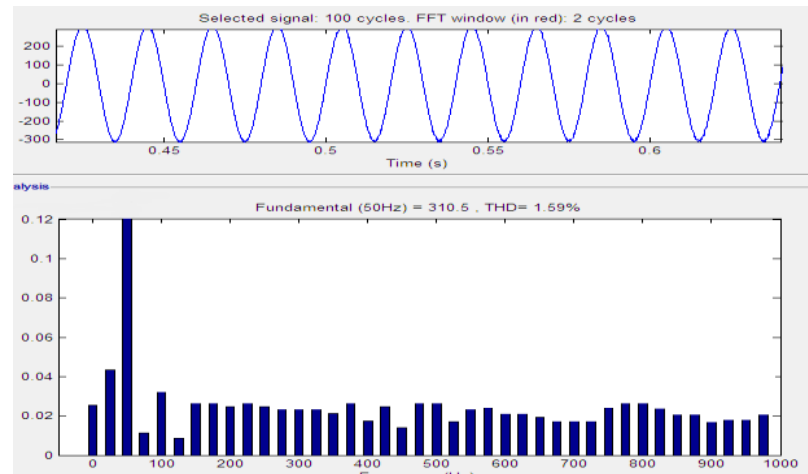

Şekil 18. Kapasitif yüklü filtreli sistemin FFT sistem genlik spektrumu

Şekil 17'de analiz diyagramından ve Şekil 18'de genlik spektrumundan kapasitif yüklü sistem için örnek verecek olursak (0.5-0.7) t sürelerinde genliğini koruduğunu 3., 5., 7., 9. harmonikleri sıfırlara çektiğini arada kalan yarım değerli 3.5, 4.5, 5.5, 7.5' deki değerlerde de araharmonik tanımladığımız nonlinear dengesizliklerin elimine edildiği gözükmektedir. Şekil 19'da farklı yükteki sistemin akım dalga verileri gösterilmiştir.

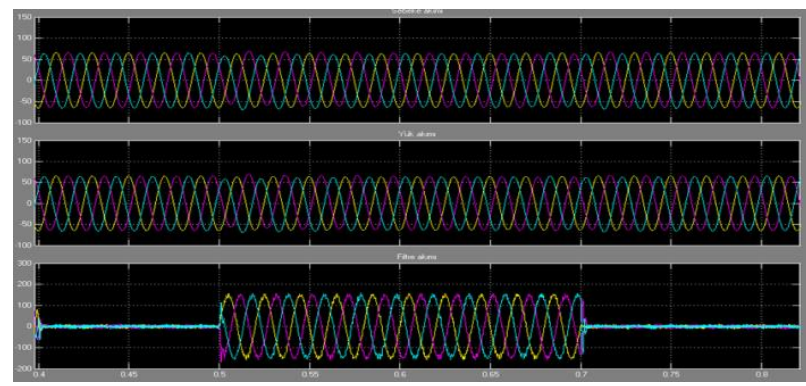

Şekil 19. Farklı yükteki güç sistemindeki akım dalga verileri

FFT analizi ile sistemin filtreye karşı vermiş olduğu sonuçları ayrıntılı şekilde liste halinde yapılmış ve gösterilmiştir. Harmonikler ve seçilen araharmonikleri için filtreden önceki yük uçlarından ve filtreyi kullandıktan sonraki yük uçlarından analizi yapılıp Tablo halinde sunulmuştur. Birkaç noktadan karşılaştırma yapılarak gösterilmiştir. Tablo 2'de SAGF'tan önceki kapasitif yük ucunun, Tablo 3'de SAGF'tan sonraki kapasitif yük ucunun ve Tablo 4'de 
filtreden önceki ve filtreden sonraki elde edilen veriler karşılaştırılarak sistem değerleri sunulmuştur. Alınan FFT analiziyle harmonikler için sonuçların hem çok düşük seviyeye getirildiği hemde seri aktif güç filtresi sistemdeyken harmonikleri elimine ettiği tespit edilmiş olup karşılaştırmalar Tablolar halinde gösterilmiştir.

Tablo 2. Filtreden önceki kapasitif sistem yük ucu FFT sistem gerilim harmonik analizi

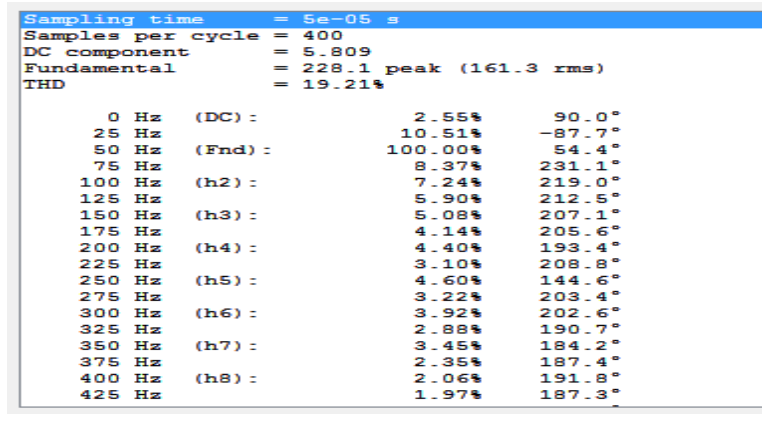

Tablo 3. Filtreden sonraki kapasitif sistem yük ucu FFT sistem gerilim harmonik analizi

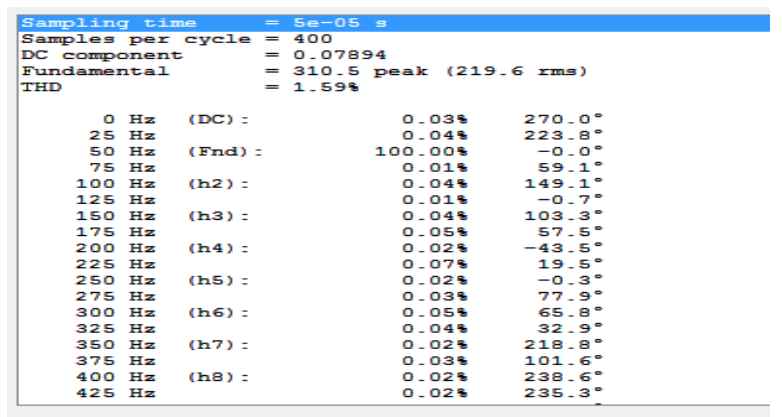

Tablo 4. Filtresiz ve filtreli durumda sistemin Gerilim ve $\mathrm{THD}_{\mathrm{v}}$ değerleri

\begin{tabular}{|c|c|c|c|}
\hline \multicolumn{2}{|c|}{} & $\begin{array}{c}\text { Sistem } \\
\text { Gerilim } \\
\text { Sistem }\end{array}$ & $\begin{array}{c}\text { Sistem } \\
\text { Gerilim (V) }\end{array}$ \\
\hline $\begin{array}{c}\text { Kapasitif } \\
\text { Yük } \\
\text { Durumu }\end{array}$ & Filtresiz & 19.21 & $219.6 \mathrm{RMS}$ \\
\cline { 2 - 4 } & Filtreli & 1.59 & $161.3 \mathrm{RMS}$ \\
\hline
\end{tabular}

Sistem incelendiğinde alınan verilerin Tablo 2 ve Tablo 3'ün ayrıntılı analizi, önemli bilgilerin edinilmesini sağlamıştır. Harmonik ve araharmonik değerlerin eliminasyonunun görülmesini sağlamıştır. Harmonik ve araharmonik bozulma değerleri farklı yükler için karşılaştırmalı gösteriminde elde edilen kazanımlar sunulmuştur. Çalışmanın daha iyi anlaşılması için sonuçlar Tablo 5'de verilmiştir.
Tablo 5. Kapasitif yükün SAGF'a karşı vermiş olduğu gerilim sonuç değerleri

\begin{tabular}{|c|c|c|}
\hline Harmonik & $\begin{array}{c}\text { Yükteki Filtreden } \\
\text { Önce Harmonik } \\
\text { Bozulma (\%) }\end{array}$ & $\begin{array}{c}\text { Yükteki Filtreden } \\
\text { Sonra Harmonik } \\
\text { Bozulma (\%) }\end{array}$ \\
\hline 3 & 5.08 & 0.04 \\
\hline 3.5 & 4.14 & 0.05 \\
\hline 5 & 4.60 & 0.02 \\
\hline 5.5 & 3.22 & 0.03 \\
\hline 7 & 3.45 & 0.02 \\
\hline 7.5 & 2.35 & 0.03 \\
\hline
\end{tabular}

Tablo 5'ten kapasitif yükteki seri aktif güç filtresi için örnek verecek olursak, filtre kullanmadan önce 3. harmonikteki bozulma \%5.08'dir. Seri aktif güç filtrenin sisteme alınmasıyla 3. harmonikteki bozulma filtrenin eliminasyonuyla \%0.04'e düşmüştür. Kapasitif yük ucundaki araharmonik olarak tanımlanan yani tamsayı değerine denk gelmeyen 3.5'teki harmonik bozulma \%4.14'dir. Seri aktif güç filtrenin sisteme alınmasıyla 3.5'teki harmonik bozulma filtrenin eliminasyonuyla $\% 0.05$ 'e düşmüştür. Seri aktif güç filtremizin tercih sebebi olarak ta sonuçların gösterdiği şekilde istenmeyen nonsinüzoidal dalga şekline sürekli karşılık verdiği, gerilim dengesizliğini elimine ettiği, ideal sinüzoidal dalga şeklini çıkardığı görülmektedir.

\section{SONUÇ VE ÖNERILER}

Şebekede akan harmonik akımlar şebeke empedansında gerilim düşümüne yol açar ve bu da gerilim dalgasının formunun bozulması, kayıpların artması, şebekede kullanılan cihazlarda arızaların veya aksaklıkların oluşmasıyla sonuçlanır. Söz konusu sonuçlar, harmonik kaynakların sistemdeki yeri, iletim ve dağıtım sistemlerindeki yayılımı ve şebeke karakteristikleri ile bağlantılıdır.

Yapılan çalışmada örnek alınan farklı tipteki nonlineer yüklü güç sistemi için seri aktif güç filtresi kullanmadan önceki ve kullandıktan sonraki harmonik ve araharmonik bozulma seviyelerini elde etmek için sistemin MATLAB/Simülink programında modüle edilerek, simülasyonu yapılmıştır. Detaylı bir FFT analiz yöntemiyle incelemesi yapılan karşılaştırmalı spektrum ve Tablo analiz sonuçlarıyla, seri aktif güç filtreden önceki ve seri aktif güç filtreden sonraki 3 faz sistemin filtreden önceki kapasitif yüklü nonlineer yükün $\mathrm{THD}_{\mathrm{v}}$ oranının \%19.21 olduğu, filtreyi kullandıktan sonraki kapasitif yüklü nonlineer yükün $\mathrm{THD}_{\mathrm{v}}$ oranının \%1.59'lara kadar azaldığı görülmüştür. Harmonik gerilim stabilizasyonunun gerçekleştirildiği ve oluşan harmonik frekanslar etrafındaki bir tamsayıya karşılık gelmeyen 
araharmoniklerin de negatif bir etkisinin olduğunu bunların da yok edilmesi gerektiği gözlemlenmiştir.

Güç kalitesi güç sistemindeki dikkat edilmesi gereken önemli problemlerden birisidir. Pasif güç filtresi ile yapılan harmonik çalışmalar ve harmonik filtreleme, doğrusal olmayan yüklerin güç kalitesi üzerindeki etkilerini engellemek için yeterli değildir. Bundan dolayı da devreye aktif güç filtresi girmektedir. Seri aktif güç filtresinin üstün özellikleri;

1) Harmonik ve araharmonikleri çok yüksek oranda filtreleme özelliği,

2) Harmonik değişimlerine milisaniyeler içerisinde çok hızlı cevap verme özelliği sonucu değişken yük koşullarında yüksek harmonik bastırma oran1,

3) Geniş bir yelpazedeki harmonikleri filtreleme özelliği,

4) Harmonik seviyelerinden bağımsız tasarım, birçok sisteme kolaylık ile uygulanabilme özelliği,

5) Şebeke empedansından bağımsız çalışma şebeke ile rezonansa girmeme özelliği,

6) Aşırı yüklenme durumu olmaması,

7) Seri aktif güç filtrenin harmonik kompanzasyon gücünün istenildiği zaman arttırılabilmesi, şeklinde sıralana bilir.

Sonuç olarak harmoniklerin varlığg, elektrik sistemlerinin çalışmayacağı anlamına gelmemektedir. Bunun için filtrenin kendisinin de bir harmonik kaynağ ${ }_{1}$ olduğu göz önünde bulundurulursa, bu hassasiyetlerin tasarım sürecinde dikkate alınması gerektiğini göstermektedir.

\section{Kaynaklar}

[1] Rüstemli S , Cengiz MS , Dinçer F, 2013. Elektrik Tesislerinde Harmoniklerin Aktif Filtre Kullanılarak Yok Edilmesi ve Simülasyonu. BEÜ Fen Bilimleri Dergisi 2(1): 30-38.

[2] Rüstemli S, Okuducu E, Almali MN, Efe SB, 2015. Reducing The Effects Of Harmonics On The Electrical Power Systems With Passive Filters. Bitlis Eren Univ J Sci \& Technol 5 (1): $1-10$.

[3] Rüstemli S, Cengiz MS, 2016. Passive Filter Solutions and Simulation Performance in Industrial Plants, Bitlis Eren Univ J Sci \& Technol 6 (1): 39-43.

[4] Rüstemli S, Cengiz MS, 2015. Active Filter Solutions İn Energy Systems. Turkish Journal of Electrical Engineering \& Computer Sciences, 23: 1587-1607.

[5] Şahin Ö, 2003. Elektrik Güç Sistemlerinde Harmonik Analizi. Yüksek Lisans Tezi İstanbul Teknik Üniversitesi Fen Bilimleri Enstitüsü.

[6] Şahin YG, 2006. Harmoniklerin Yeraltı Güç Kablolarına Etkisi. Kocaeli Üniversitesi Fen Bilimleri Enstitüsü.
[7] Zenger M. Akım ve Gerilim Harmonikleri. www.harmonik.wsmustafazenger@gmail.com.

[8] Kocatepe C, Uzunoglu M, Yumurtac1, R, Karakas A, Arıkan O, 2003. Elektrik Tesislerinde Harmonikler, Birsen Yayınevi, İstanbul.

[9] Chapman D. "Harmonikler, Nedenleri Ve Etkileri" Copper Development Association.

[10] Karakaş A, Kocatepe C, Baysal M, Çakır H, 2005. Harmonikli Sistemlerde Filtre Uygulamasının Karşılaştırılması, Enerji Verimliliği ve Kalitesi Sempozyumu. Kocaeli, 17-18.

[11] Ellis RG, 1996. Harmonic analysis of industrial power systems, IEEE Transactions on Industry Applications, Vol.32, 2: 417-420.

[12] Demirören A, Zeynelgil L, 2004. Elektrik Enerji Sistemlerinin Kararlılı̆ 1 , Kontrolu ve Çalışması. İstanbul, 1:204-238.

[13] Odabaşı T, 2004. 3. Harmoniğin meydana getirdiği problemler. www.etmd.org.tr.

[14] Sucu M, 2003. Elektrik Enerji Sistemlerinde Oluşan Harmoniklerin Filtrelenmesinin Bilgisayar Destekli Modellenmesi ve Simülasyonu. Yüksek Lisans Tezi, Marmara Üniversitesi Türkiye.

[15] Akagi H, 1996. New Trends in Active Filters For Power Conditioning, Industry Applications, IEEE Transactions on, 32: 1312-1322.

[16] El-Habrouk M, Darwish K.M, Mehta, P, 2000. Active power filters: A review, Electric Power Applications, IEE Proceedings, 147: 403-413.

[17] Li D, Tian J, 2008. A Novel Active Power Filter for the Voltage-Source Type Harmonic Source, Electrical Machines and Systems. ICEMS 2008. International Conference on, Wuhan, HUST, 2077 - 2080 (in China).

[18] Singh B, Al-Haddad K, Chandra A, 1999. A Review of Active Filters for Power Quality Improvement. Industrial Electronics, IEEE Transactions on, 46: 960-971

[19] Peng ZF, Adams JD, 2001. Harmonic Sources and Filtering Approaches. Industry Applications Magazine, IEEE, 7: 18-25

[20] Tekev S., 2021. Güç Sistemlerindeki Harmoniklerin ve Araharmoniklerin Bilgisayar Destekli Modellenmesi ve Simülasyonu Bitlis Eren Üniversitesi Lisansüstü Eğitim Enstitüsü 